\title{
Socialismo popular Una propuesta socialista desde el tercer mundo
}

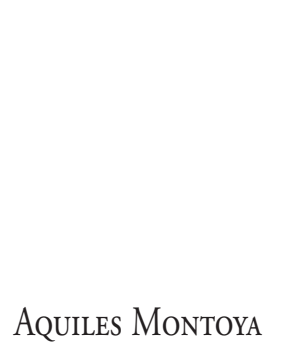

\section{Introducción}

$\Lambda$ nte el hecho harto publicitado del derrumbe de algunos modelos de socialismo, los ideólogos del capitalismo han venido saltando de contentos: algunos porque se percatan de la transcendencia geopolítica que representa la desintegración de la URSS, otros, porque mal entienden tal fracaso como un triunfo del capitalismo y otros más, porque asocian tal caída con un presunto descrédito de la teoría marxista.

Por otra parte, algunos izquierdistas, para beneplácito de la derecha, se sienten desorientados y caen prisioneros de las ilusiones del sistema y terminan jugando el juego del capitalismo; otros, buscan recomendar para nuestros países algunas acciones de emergencia implementadas por los socialistas cubanos, sin detenerse a considerar que en Cuba se vive una realidad, a todas luces, incomparable con la realidad latinoamericana, Cuba sigue siendo un país socialista.

Pero existen otros, para quienes siguen siendo evidentes los límites que presenta el capitalismo y en consecuencia, les resulta obviamente necesario persistir en la búsqueda de algo alternativo al mismo. Queremos sentirnos parte integrante de éstos y aunque le resulte molesto, inclusive a la derecha progresista, es preciso decir que si bien en el país algo ha cambiado, no es como para terminar creyendo que todo está bien y que aquello que no lo está, se corregirá como fruto "del desarrollo y la democracia" en el capitalismo. Este es el discurso de la derecha que se siente muy cómoda y a gusto con los cambios cosméticos de El Salvador de hoy, porque disfruta de los beneficios del sistema sin las aprehensiones del pasado. Pero esta no es la realidad de las grandes mayorías de salvadoreños, ni de los latinoamericanos, ni de los habitantes del tercer mundo, ni de la gran mayoría de la humanidad. Y mientras sigamos viviendo en un mundo que es de una minoría, no sólo existe el derecho sino el deber, de pensar y de trabajar por cons-

truir una sociedad diferente. 
Y a propósito del llamado de los empresarios salvadoreños: "Hoy le ofrecemos a la intelectualidad salvadoreña, que volvamos a coincidir en la importancia vital de la democracia, pidiéndole que trabaje en una teoría de la transición a la democracia, con el fin de que nos ilumine para tenerle paciencia." ${ }^{2}$ Debemos decirles que somos partidarios de la democracia y creemos que es preciso defender la poca que tenemos y trabajar por ampliarla hasta los límites que la permita el sistema, pero debemos estar claros que democracia no es sinónimo de capitalismo, porque el capitalismo niega precisamente la democracia económica, la cual es el fundamento de la democracia real. A menos que pensemos que la democracia no pueda ser otra que aquella que forjaron los griegos, en la cual la mayoría no vivía en democracia, porque ni siquiera se les reconocía sus derechos políticos, ya no digamos sus derechos económicos.

Por otra parte necesario es aclarar que la intelectualidad centroamericana no "se dejó seducir por la utopía socialista", sino que en la búsqueda de una sociedad alternativa a la capitalista, a partir del reconocimiento de los males inherentes e insuperables del mismo, encontró en el socialismo una posible opción, la cual sigue siendo válida todavía, aunque se difiera en la actualidad respecto al modelo particular de socialismo o se hayan desvalorado las opciones violentas de toma del poder para transformar desde arriba a toda la sociedad. Pero allí no más está el socialismo cubano, mostrando a la faz del mundo de lo que es capaz una sociedad socialista, al haberse ubicado en el OCTAVO LUGAR a nivel mundial en los recién pasados juegos olímpicos, lo cual obviamente no es fruto del azar, ni de la suerte, sino de la preocupación que se tiene en tal sociedad por la práctica deportiva. Cuando Cuba, un país tercermundista y sufriente por el soberbio bloqueo yanqui, se ubica en el medallero olímpico por encima de grandes potencias industriales como Japón y sus comparsas del sudeste asiático, por ejemplo, lo menos que se puede pensar es que se trata de un pueblo saludable y bien alimentado, algo de lo que no pueden hacer alarde las derechas latinoamericanas.

En este ensayo nos vamos a ocupar de presentar algunas ideas en torno a lo que podría ser un sistema alternativo al capitalista. Como es de esperar sólo nos habremos de referir a algunos tópicos de la actividad humana en ese supuesto sistema alternativo y entre ellos, a aquellos aspectos que, a nuestro juicio, son los más relevantes en el mismo, en la medida que lo hagan ser algo nuevo y esencialmente diferente. Aunque, obviamente, se trata de una construcción teórica, no es una construcción puramente especulativa, sino que busca rescatar de la realidad presente todo aquello 
que se presente como novedoso $y$ de beneficio para la sociedad humana. En consecuencia, partiremos de aquellas experiencias positivas, las cuales al ser desplegadas o extrapoladas - con algunas modificaciones, por supuesto- nos permitan construir una totalidad nueva, al menos, en algunos de sus elementos esenciales. Necesario es aclarar también que el esfuerzo se realiza desde el tercer mundo y pensando precisamente en nuestra realidad.

En la medida en que el trabajo exige evitar los errores cometidos en el pasado en los países socialistas europeos, así como superar los males propios del capitalismo, proponer algo alternativo que sea suficientemente abstracto para servir de horizonte en cualquier realidad y suficientemente realista para no caer en la fantasía pura, sin base ni fundamento en los hechos, pero sin reducirse a una mera descripción de los mismos, resulta una tarea excesiva para una sola mente; sin embargo, ello no ha pesado tanto como para inducirnos a la parálisis mental, pero si a reconocer lo limitado de nuestro esfuerzo y la necesidad de la concurrencia de otros que compartan esta búsqueda, ya sea para desarrollar o corregir lo propuesto.

Para concluir esta larga aunque necesaria introducción queremos explicitar que este ensayo tiene dos propósitos: el primero es de- cir a quienes se regodean por la presunta muerte del socialismo: la utopía no ha muerto. Y el segundo es animar y ubicar en una perspectiva de futuro los esfuerzos de los sectores populares y de quienes les acompañan. El esquema a seguir está conformado por tres partes: en la primera postulamos una serie de proposiciones, a nuestro juicio de una realidad tan obvia, que bien merecen ser considerados como hechos y que en su realidad fáctica no amerita el sustentarlos. No obstante lo anterior, también podrían ser considerados como meros supuestos, aunque por la naturaleza ensayística del trabajo nos eximimos de la necesidad de fundamentarlos. En la segunda parte nos concentramos en describir los elementos conformadores de la nueva organización social que proponemos. Como ya lo hemos señalado, no pretendemos más que mostrar algunos rasgos del boceto de lo que podría llegar a ser una sociedad o un sistema alternativo al capitalista. Necesario es destacar que se trata de un horizonte, de un punto de llegada y consecuentemente, que ya se han superado una diversidad de obstáculos. Y finalmente, proponemos algunos elementos sobre lo que se podría considerar como la transición hacia esa sociedad utópica y un apartado en el cual buscamos dar respuesta a las acostumbradas interrogantes cuando se trata de este tipo de propuestas. 


\section{Postulados}

\subsection{El esquema básico:}

Un fenómeno que es preciso superar en una sociedad alternativa a la capitalista es el fenómeno de la explotación, el cual radica y se fundamenta en la propiedad capitalista de los medios de producción y circulación. Así como también la expoliación que caracteriza a las relaciones entre las formas económicas capitalistas y las no capitalistas, las cuales presentan un mayor desarrollo en los países del tercer mundo.

El superar la explotación del trabajo asalariado es una condición necesaria, pero no suficiente, ya que pudiera cambiarse su modalidad e incluso superarse temporalmente, tal cual ocurrió en el socialismo de la Europa Oriental y no obstante ello, resurgir ulteriormente tras modalidades inéditas, cuales serían las relaciones entre tecnoburócratas y los trabajadores, bajo el fundamento de la propiedad estatal. ${ }^{3}$ Por otra parte, la expoliación es el mayor problema que enfrentan las formas económicas alternativas inmersas en el sistema capitalista, de allí que para disminuirla, sea recomendable la búsqueda de articulación entre sí mismas y disminuir al máximo posible las relaciones con las diferentes modalidades del capital.

Íntimamente vinculada a la explotación está la racionalidad eco- nómica, la cual en el capitalismo se reduce al postulado siguiente: búsqueda de maximizar las ganancias y minimizar los costos, lo cual si bien en términos de eficiencia ha funcionado relativamente bien, — sin olvidar, por supuesto, el carácter depredador de la vida que ha acompañado a tal lógica económica- no se puede decir lo mismo en términos de justicia y bienestar mayoritario.

La racionalidad económica hace referencia, fundamentalmente, a dos elementos: la eficiencia y la participación en el excedente generado en cualquier economía.

Si nos detenemos por un momento en la eficiencia, la cual nos remite a la tecnología, parece claro que el capitalismo, con su magistral desarrollo de la técnica, ha superado a todos los sistemas conocidos, sin despreciar, obviamente, los aportes brindados por el socialismo y el carácter antiecológico de ambos sistemas en cuanto a su correspondiente estilo de desarrollo industrial. Sin embargo, la técnica necesita personificarse en los seres humanos, de allí que históricamente encontramos que un hecho posibilitante de la eficiencia económica en cualquier sociedad es la participación consciente del trabajador en la actividad económica, lo cual no siempre ha sido posible en las unidades económicas capitalistas, ni 
socialistas, aunque en la actualidad se presente como un objetivo a alcanzar en el capitalismo, pero para que se convierta en realidad exige de una participación mayor en los beneficios, lo que podría significar el principio de la negación del sistema capitalista.

Los presupuestos de la participación consciente son la información, la capacidad y el interés económico del trabajador. Pero el interés económico del trabajador en la empresa capitalista está limitado por su no propiedad de los medios de producción y circulación. Semejante es el caso en el socialismo real, donde la no propiedad del trabajador se esconde tras la propiedad del estado, tal cual ocurrió en la mayoría de modelos de socialismo.

En cuanto al otro elemento de la racionalidad económica, cual es la participación en el excedente, encontramos que puede ser equitativa e inequitativa. Si está fundamentada en la explotación será inequitativa, si no lo es podría ser equitativa. De allí que es clave la superación de la explotación, la cual como ya mencionábamos no es posible lograrla en el capitalismo y no ha resultado satisfactoria la forma implementada en los modelos de socialismo real.

En la búsqueda de la equidad, que esté acorde con la racionalidad económica, encontramos que un factor que podría ser posibilitante de la participación equitativa sería la sustitución de la propiedad capitalista y de la propiedad estatal por la propiedad democrática. Esta tendría que ser la propiedad de los trabajadores, en razón de que la propiedad privada capitalista es fuente de la explotación y de la inequidad y la propiedad estatal, como lo mostró el socialismo real, tampoco logró la equidad, ni la eficiencia de manera sostenible $y$ sostenida.

\subsection{El mercado:}

Mientras no se logre alcanzar la abundancia en la producción de bienes y servicios, ni la austeridad fruto del consumo racional, será preciso admitir la asignación que posibilita el mercado, la cual no sería tan desastrosa en la medida que TODAS las personas tengan empleo y/o ingresos que les posibiliten adquirir los bienes y servicios necesarios para su reproducción material y espiritual.

El mercado de suyo no es nocivo, ya que el mercado es un abstracto, el problema se origina en que existen demandantes y oferentes concretos. En consecuencia, cuanto más concentrado esté el ingreso o la producción de bienes y servicios, peor funcionará el mercado. De allí que si desea aprovechar los atributos del mercado es preciso que opere en ausencia de monopolios y, o monopsomios, lo cual, 
obviamente, no significa proponer la competencia capitalista.

El mercado capitalista tiende por su propia naturaleza a enfrentar tales problemas y el mercado socialista no logró encontrar una respuesta adecuada mediante el empleo de la planificación. De allí que la búsqueda debería de orientarse, no a eliminar el mercado, sino a hacer que funcione de manera eficiente y ello presupone condiciones propias de una circulación mercantil simple, esto es, que la gran mayoría de oferentes y demandantes sean productores propietarios, que orienten sus esfuerzos a obtener sus medios de vida y no una ganancia y que sus niveles de ingresos no sean excesivamente diferenciados, lo cual sería la resultante de la inexistencia de concentración en la propiedad de los medios de producción y circulación. ${ }^{4}$

\subsection{El gobierno:}

Un gran mal común a las sociedades capitalistas y socialistas es la existencia desmedida de parásitos sociales, los cuales encuentran su justificación en los aparatos gubernamentales, tales como los políticos, los burócratas y los militares. En consecuencia, es preciso encontrar la forma de evitarlos, reducirlos o cambiar el carácter profesional de su actividad, cuando ello fuera factible. Tal concepción no busca eliminar cualquier forma de gobierno, sino reducirlo a aque-
Ilas actividades que, por su misma naturaleza, le resulte a la sociedad más conveniente delegarlas a un entes colectivo que efectivamente se ocupe del bien común.

Tal visión cuestionadora del aparato estatal pudiera parecer propia de una concepción neoliberal; sin embargo debemos declarar y aclarar: en primer lugar, que nuestra postura es muchísimo más radical que la concepción neoliberal, en tanto no se trata sencillamente de abrir espacios a la valorización del capital vía la privatización de activos públicos; en segundo lugar, no es hipócrita, cual sí lo es la práctica neoliberal, ya que los aparatos estatales en los países capitalistas desarrollados son gigantescos, basta con pensar en los recursos humanos y materiales destinados el área militar y a las agencias de seguridad, ya no digamos las burocracias federales, estatales y locales; en tercer lugar, se trata de un punto de llegada, lo cual obviamente presupone una presencia significativa del gobierno en la transición. Y finalmente, la reducción-modificación del gobierno es una resultante de lo innecesario de sus actividades. Además, si todas las personas pueden comprar -O adquirir de otra manera- los bienes y servicios que necesitan, resulta un absurdo que los proporcione el gobierno de manera gratuita, nos referimos a satisfactores tales como la educación, la salud, la vivienda, la energía, el agua, las comunicaciones, etc. Y por el contrario 
los servicios de justicia, seguridad pública, orden, seguridad y sanidad ambiental, etc. deberían de prestarse de manera gratuita y sin discriminaciones, cosa que no ocurre, por cierto en el capitalismo.

En síntesis, nuestra visión respecto a la reducción-transformación del gobierno es una resultante en un determinado tiempo, de la atrofia de sus órganos debido al desuso de los mismos y responde al interés social general, más que a los intereses económicos particulares de una determinada fracción de la clase capitalista.

\subsection{La organización social}

Los humanos buscan organizarse con aquellos que tienen elementos comunes, cualquiera que sea la naturaleza de lo común; así encontramos en el capitalismo asociaciones de empresarios, de informarles, de profesionales, de mujeres, de campesinos, de sindicatos obreros, etc.

La nueva sociedad tendrá que buscar formas de organización que resulten adecuadas a la naturaleza social de los sujetos, a los valores que los animan y a los intereses que buscan alcanzar, proteger o hacer valer.

Podrían existir clases sociales, sin embargo la inmensa mayoría debería de estar constituida por trabajadores propietarios y consecuentemente, no cabría la posibilidad de la explotación.

\section{La utopía}

\subsection{Una sociedad eficiente, equitativa y participativa}

El modelo de organización social que buscamos proponer, debe responder en un primer momento a tres características fundamentales, cuales son: la eficiencia, la equidad y la participación, las cuales se desprenden de la perspectiva económica desde la cual hemos partido, lo cual no excluye la posibilidad de adicionarle ulteriormente otras características igualmente importantes.

a) La célula: La Organización Económica Popular (OEP) ${ }^{5}$.
Teniendo en mente los anteriores elementos, el nuevo sistema socio-económico que estamos proponiendo tendría como célula básica, a la organización económica popular (OEP), el conjunto de OEP sería el responsable de las actividades de la producción -de bienes y servicios- y de la circulación. La OEP vendría a reemplazar a la unidad económica conocida como la empresa. Y habría tantas OEP, como lo requiera la sociedad, así como variables serían sus tamaños. Pero a diferencia de la empresa capitalista o socialista, los trabajadores no sólo serían los propietarios, sino 
que participarían activamente en la conducción de la OEP, sin ningún tipo de ingerencia estatal. Ninguna OEP podría tener trabajadores asalariados, sus integrantes serían socios, en la proporción que lo determinaran las reglamentaciones sociales, atendiendo a su capacidad, a su aporte en trabajo, a su antigüedad, etc. Siendo esto así, no sólo se eliminaría la explotación sino que adicionalmente los integrantes de cada OEP estarían interesados en ser eficientes, ya que cuanto más lo fuesen mejores serían sus condiciones de vida y de trabajo, conforme a su propio esfuerzo y a su aporte, con lo cual se buscarían no el igualitarismo per se, sino la justicia, la cual exige tratar a los iguales como iguales y a los desiguales como tales.

La racionalidad de la OEP estaría determinada por la satisfacción de las necesidades materiales y espirituales de toda la sociedad, dentro de los marcos determinados por un estilo de desarrollo sostenible, ${ }^{6}$ esto, es, socialmente equitativo y ecológicamente viable. El criterio para decidir sobre una determinada inversión no sería la rentabilidad sino su impacto ambiental.

Las OEP se relacionaría con los consumidores y con otras OEP a través del mercado, el cual operaría en condiciones de competencia, sin ningún tipo de regulación interna, a no ser por las normas propias de los consumidores. En la fase de transi- ción los gobiernos podrían tener un papel bastante activo estimulando determinado tipo de producción e importantes, así como determinadas pautas de consumo, a fin de ir educando a la población conforme a la nueva racionalidad del desarroIlo sostenible. En su ultimidad no existirían estados nacionales, ya que el mundo se habría efectivamente mundializado.

No habría ninguna actividad económica, en el ámbito de la OEP, en la cual se contratara personal asalariado, aunque si podrían existir actividades unipersonales, más siempre se buscaría su evolución hacia cualquier modalidad de OEP. En consecuencia, todas las actividades económicas estarían desarrolladas por OEP, ya sea en la producción como en la circulación, esto es, tanto en la agricultura como en la industria, el transporte, la construcción, etc. o bien, en el comercio, la banca, lo seguros, los medios de comunicación, etc. Todo lo cual, no excluye la posibilidad de que las asociaciones de OEP, pudieran vender algún tipo de servicios a los integrantes de sus OEP asociadas, pero no entrarían de manera indiferenciada al mercado.

En la fase de transición la inversión extranjera sería factible pero de manera temporal. Transcurrido el tiempo pactado debería pasar a constituirse en una OEP y consecuentemente a ser propiedad de sus trabajadores. Aunque al desaparecer 
los estados nacionales no tendría ningún sentido de realidad hablar de inversión extranjera, el campo de actividad de las OEP sería el mundo. Para entender esta idea, piénsese en las empresas transnacionales pero convertidas en OEP.

b) El tejido: las asociaciones de $\mathrm{OEP}^{7}$.

Si las OEP constituyen la célula del sistema, las distintas OEP dedicadas a una misma o semejante actividad se articularían a través de sus representantes en asociaciones, las cuales constituirán el tejido del nuevo sistema socio-económico.

¿Quiénes integrarían a las asociaciones? Pues representantes electos por las distintas OEP para un tiempo determinado. Luego, entre ellos se elegiría a aquellos que dirigirán las distintas actividades de las asociaciones.

Las asociaciones estarían integradas atendiendo a criterios económicos, así tendríamos a aquellas OEP dedicadas a actividades iguales o semejantes, en razón de que la asociación velaría por satisfacer las necesidades económicas de las OEP y, o las necesidades sociales de los integrantes de las OEP. Por ejemplo, los productores de calzado o de granos básicos. En un segundo momento, atendiendo a las diferentes ramas del sector económico en el cual se ubicarán, por ejemplo, los ubicados en la rama de alimentos o en la ganadería. En un tercer momento atendiendo al sector particular de su actividad, por ejemplo industriales, constructores, etc y finalmente, con base en su ubicación geográfica. Lo anterior nos indica que existirían, al menos, cinco niveles organizativos.

Las asociaciones tendrían personal contratado a fin de atender las necesidades sociales de los agremiados y su familia, entre las cuales cabe mencionar, entre otras: salud, educación, previsión social, capacitación, ecología, asesoría jurídica, desarrollo, arte, cultura, comunicación, seguro de quiebra, etc. Tales servicios se podrían prestar directamente o contratar los servicios de OEP especializadas.

Igualmente contarán con personal especializado a fin de atender las necesidades económicas de las distintas OEP, tales como: técnicas de producción, de mercadeo, de comunicación, de administración, de investigación tecnológica, de entorno macroeconómico, de exportaciones, de exploración de nuevos mercados, productos y servicios, etc. Tales servicios se podrían prestar directamente o contratar los servicios de OEP especializadas.

Las asociaciones se financiarían con los aportes de sus agremiados y con la venta de servicios que presten a las OEP agremiadas. Importa destacar que los agremiados no serían los individuos sino las OEP. 
Se regularía mediante un estatus especial la carrera de los empleados de las asociaciones, quienes no podrían ser propietarios, lo contrario ocurriría con los representantes de las empresas, quienes deberían de ser propietarios y servir a la asociación únicamente por el período para el cual se les hubiera electo. Los empleados de las asociaciones podrían conformar sus propias organizaciones con carácter sindical.

A las asociaciones correspondería el asumir muchas de las responsabilidades que en el pasado correspondía al gobierno, la pertinencia de este cambio radica en que los asociados podrían no sólo exigir la satisfacción de sus necesidades, sino controlar el uso que se haría de sus aportaciones, a fin de garantizarse su desarrollo económico y social, en la OEP y en la familia.

A cada asociación correspondería proponer candidatos para el gobierno, los cuales serían electos popularmente, par un determinado período, sin posibilidad alguna de re-elección.

\section{c) El gobierno}

En el límite, deberían de desaparecer los estados nacionales y en consecuencia lo que debería de existir es un gobierno mundial y administraciones locales. Las funciones de gobierno mundial serían las legislativas, las judiciales y las de coordinación y apoyo al desarro-
Ilo sostenible. Las administraciones locales serían las encargadas de ejecutar las disposiciones del gobierno mundial, de administrar los recursos y de recaudar impuestos a nivel local.

Tal gobierno mundial tendría una estructura semejante al de las Naciones Unidas, pero con la diferencia que no representaría a las naciones -las cuales no existirían- sino que estaría integrada por las personalidades más relevantes a nivel mundial con capacidad demostrada en las OEP y vocación de servicio comprobada en las asociaciones de OEP o bien, en las administraciones locales.

Ningún funcionario público a nivel mundial o local sería nombrado, todos deberían de ser electos directa o indirectamente.

Lo interesante que presentaría esta forma de gobierno, además de su reducción, sería que los partidos políticos no tendrían ya razón de existir, aunque sí la política, pero se habría convertido en una más de las actividades sociales propias del ser humano. Pensamos que la democracia política perfecta es aquella en la cual no existen partidos políticos. Adicionalmente, los cargos de elección estarían reservados a aquellos dirigentes de las distintas asociaciones que hubiesen demostrado su vocación de servicio y su capacidad profesional en la práctica cotidiana. 
El gobierno procuraría que la igualdad de oportunidades fuese una realidad para todos, de allí que ninguna persona podría heredar o donar a otra u otras personas, una cantidad que superarse lo necesario para recibir una buena educación. En el capitalismo, los hijos de los burgueses no compiten en igualdad de condiciones con el resto de personas. Si se nace burgués, se cuenta con recursos materiales que no le han costado ningún esfuerzo ni trabajo a la persona, de tal manera que ello posibilita que se reproduzca una exagerada desigualdad social, a menudo inmerecidamente. En la nueva sociedad si existirían condiciones para competir en condiciones de igualdad, ya que las oportunidades de educación y capacitación serían iguales para todos, las diferencias podrían generarse en la vocación, el esfuerzo o el talento de las personas. Lo cual, ciertamente, no daría lugar a privilegios de ningún tipo, ni tendría por qué se mal visto.

\subsection{Una sociedad ecológicamente viable, económicamente sostenible y sin discriminación genérica}

A fin de llegar a constituimos en una sociedad ecológicamente viable, lo primero que habría que transformar sería la mentalidad consumista generada por el capitalismo y dar paso a la civilización del consumo racional tanto en cantidad como en calidad y adicionalmente, ser éticamente responsable en cuanto a lo que se consume. Si lo anterior va aparejado con una producción que no sea contaminante, ni destructora de los equilibrios biológicos es claro que podríamos contar con una sociedad ecológicamente viable. Todo lo cual presupondría contar con tecnologías ambientalistas, en las cuales existiera no sólo una preocupación por la productividad sino también por la preservación de los ecosistemas locales y el ecosistema mundial. Ello sería posible en la medida que la racionalidad capitalista hubiera sido reemplazada por la nueva racionalidad económica: cuyo fundamento sería la vida, no sólo de los seres humanos, sino de toda forma de vida.

Parece claro que para poder alcanzar una organización social ambientalista, sería preciso que los humanos viviéramos en austeridad, lo cual de ninguna manera significativa vivir en la pobreza, sino consumiendo tan sólo aquello que es necesario para tener una vida digna, agradable y plena. Todo lo opuesto a la sociedad consumista en la cual vivimos. Como este aspecto es de suma transcendencia para nueva organización social, pensamos que su desarrollo tiene mayor viabilidad entre los pobres de este mundo, ya que la austeridad se presenta como un estudio superior en relación a la condición de pobreza y marginación social de la gran mayoría de la humanidad. 
Las distintas ONG ambientalistas jugarían un papel muy importante durante la transición y podrían llegar a conformar en el nuevo sistema una institución social garante, promotora y facilitadora del desarrollo ecológico.

El carácter sostenible del nuevo sistema se deriva de su fundamentación en las organizaciones económicas populares y en las asociaciones populares de trabajadores propietarios, las cuales posibilitan la eficiencia y la equidad social, al actuar con una lógica económica que tendría como objetivo asegurar la reproducción material y espiritual de las personas, pero que desde una perspectiva mayor sería una lógica que fuera garante de la vida, de toda forma de vida.

La discriminación genérica ha comenzado a ser cuestionada y a ser socialmente inaceptable, tanto en el capitalismo como en el socialismo. Nos parece que tal tendencia ha encontrado su fundamento en la independencia económica que ha ido consiguiendo la mujer. En la nueva sociedad, al ser una sociedad de trabajadores propietarios libres y asociados, la discriminación genérica no tendría ninguna razón de ser, ni justificación alguna, y adicionalmente existirían las condiciones objetivas para que la mujer pudiera desempeñar cualquier actividad que desee, lo cual significa que, inclusive, las ataduras propias de la familia estarían cortadas, lo cual posibilitaría destruir la cultura machista y generar una nueva cultura fundamentada en la igualdad de géneros.

\subsection{Una sociedad profundamente humana, saludable y culta}

El máximo derecho de las personas sería el derecho a la vida. De allí que, por ninguna razón ni circunstancia alguna, sería dable atentar contra la vida de las personas. Las armas mortales deberían de ser proscritas y destruirse todas aquellas existentes. A los niños se les enseñaría desde muy temprana edad el respeto por la vida y lo deshonroso y estigmático que sería atentar contra la vida humana. Los asesinos deshonran a toda su descendencia y nada ni nadie puede limpiar la sangre derramada. Pero, además de respetarse la vida misma, se generarían las condiciones necesarias para vivir con dignidad, lo cual presupone elevar los niveles de educación básica, de cultura y de capacitación técnica y científica.

El deporte en todas sus manifestaciones sería parte de la educación personal, no sólo en la infancia y juventud, sino durante la edad adulta y la tercera edad. Así como habría horas para trabajar, las habría también para practicar deportes o dedicarse a actividades culturales, lo cual presupone una disminución significativa de la jornada diaria de trabajo. 
La actividad deportiva tendría también un carácter profesional y los diferentes deportistas constituirían OEP dedicadas a la venta de su espectáculo, mientras estuviesen en condición de practicarlo. Posteriormente deberían de incorporarse a otras actividades para las cuales se hubiesen capacitado.

Los artistas no serían considerados como seres especiales, sino como lo que son: trabajadores del arte y la cultura y en consecuencia conformarían OEP para vender sus productos o servicios, atendiendo a las necesidades de las personas, las cuales se manifestarían por medio del mercado. En consecuencia, su trabajo sería el medio que les posibilitaría satisfacer sus necesidades, lo cual conseguirían, mejor o peor, dependiendo de la calidad de su producción. Lo que si cabe esperar es que habría una demanda bastante elevada de arte y cultura, porque se contaría con los ingresos suficientes no sólo para satisfacer las necesidades materiales, sino que también las espirituales. Y todavía mejor, ya que la población recibiría una educación integral, la cual despertaría nuevos apetitos espirituales.

En la nueva sociedad se promocionaría las actividades contemplativas de la naturaleza y sus fenómenos, como formas de distracción. Los humanos necesitan redescubrir el placer de contemplar un atardecer, el romanticismo de una noche de luna, la tranquilidad de las aguas quietas, la reflexión que propicia un cielo estrellado, el encanto del trinar de los pájaros, la ternura de los animales recién nacidos, los fortificante de un paseo por prados ornados de rocío, lo encantador de leer bajo la sombra de los árboles, etc., y despegarse de los idiotizantes aparatos de televisión.

Pero hacer posible ese reencuentro del humano con la naturaleza presupone no sólo garantizar la vida misma, sino que los humanos superen su soberbia y se vean como lo que son, como una forma más de naturaleza. Lo social y lo natural no tienen porqué contraponerse.

\subsection{Una sociedad democrática en lo social, lo político y lo económico}

En la nueva sociedad no deberían de existir sitios o lugares sociales excluyentes de ningún tipo. Lo clubes o lugares vedados por razones económicas, por ejemplo, propios del capitalismo, deberían de democratizarse. De igual manera los lugares de descanso con carácter escaso como suelen ser las playas en mares, lagos y lagunas deberían de socializarse. Los centros de estudio, de actividades recreativas, de prácticas deportivas, etc. deberían de perder su carácter etilista.

Ninguna persona debería ser marginada socialmente en razón de su raza, cultura, ideas, credos, 
sexo, condición económica o lugar de trabajo, etc.

El fundamento para tal realidad social propuesta, sería reconocer, primero, la dignidad de la persona humana, segundo la importancia del trabajo en tanto generador de riqueza social y tercero, el hecho de que no existirían personas que no contaran con los ingresos necesarios para satisfacer sus necesidades, en consecuencia no tendrían porque existir ciudadanos de primera, segunda o tercera categoría. Lo cual no significa que se esté propiciando un igualitarismo forzado, existirían diferencias en los ingresos, lo cual generaría diferencias sociales, pero éstas no deberían de ser abismales, ni tampoco posibilitar la discriminación social.

La práctica política deberá recobrar su contenido esencial, esto es, el interés por la sociedad y en consecuencia, podría y debería de ser realizada por todos los ciudadanos, como una faceta más de su quehacer social, sin necesidad de que existan institutos políticos, que mediaticen esta práctica humana y que, inclusive, reemplazan a los ciudadanos. Es más, los partidos hacen gobiernos de partidos, los cuales, a menudo, devienen en dictaduras partidarias. Por otra parte, si se pretende establecer un gobierno mundial, resulta obvio que éste deberá ser pluralista, tarea que se dificultaría mediante la existencia de diversos partidos, o bien, se terminaría conformando un gobierno representativo de las diferentes corrientes político-ideológicas partidarias y no de los ciudadanos del mundo.

La democracia económica estaría asegurada a partir del hecho de que la actividad económica sería realizada, en su casi totalidad, por trabajadores propietarios, los cuales participarían en la distribución del excedente generado y distribuirle de manera proporcional a su propiedad. Los empleados del gobierno y de las asociaciones de OEP deberían tener ingresos que fuesen semejantes a los ingresos de los trabajadores propietarios dependiendo de su capacidad, actividad, antigüedad, etc.

\section{La transición}

Como habrán podido apreciar quienes conozcan mis trabajos acerca de la nueva economía popular (NEP), este ensayo trata de la continuación de la misma temática, ahora proyectada a toda la sociedad y adicionalmente, presupone que se ha avanzado en el desarrollo de las premisas que en aquél hubimos de señalar. ${ }^{8}$

Además de esa diferencia, la cual es fundamental, ya que en la nueva economía popular insistía- 
mos en que no se trataba de un modelo o un sistema, pero que en su límite podría llegar a constituirse en tal, presenta otras diferencias importantes, algunas derivadas de su pretensión sistémica, como lo es por ejemplo, el hecho de que ahora no se excluye a nadie, aunque sí exige algunas reconversiones para algunas castas y para algunas clases sociales. Así tenemos que perfectamente caben los empresarios capitalistas, en la medida que decidan trabajar en una OEP, y dejar de ser capitalistas, o bien dedicarse a descansar gozando de una pensión vitalicia.

Otro elemento importante es que esta concepción ya no se reduce a un proyecto para el tercer mundo, ya que las empresas y las diferentes actividades del primer mundo perfectamente pueden ser transformadas en OEP, las empresas transnacionales serían las más fácilmente convertibles en OEP, ya que en sus estructuras organizativas y administrativas, a menudo, ni figuran ya los propietarios.

\section{1. ¿Cómo avanzar hacia la construcción de la nueva sociedad?}

Obviamente existen varias vías. Habremos de señalar solamente algunas, pero ninguna de ellas se fundamenta en un cambio violento, rápido, ni por lo decreto, lo cual no impide que el cambio sea revolu- cionario. Por otra parte, las distintas vías no son excluyentes sino que son complementarias.

La primera vía está fundamentada en el apoyo, desarrollo y consolidación de las distintas organizaciones económicas populares (OEP) ya existentes en la actualidad. Nos referimos a todos aquellos entes que constituyen los sujetos reales de la nueva economía popular. Obviamente, está también la creación de nuevas OEP, labor en la cual pueden ser de mucha ayuda las distintas ONG existentes. Pero pasa que esta vía cobre toda la importancia que tiene es preciso que los políticos de izquierda y todos aquellos que compartan el repudio por la sociedad capitalista, vean en el trabajo de apoyo a los pobres organizados, algo más que una labor humanitaria, ya que de hecho se trata de construir los cimientos de una nueva sociedad, de allí que la solidaridad internacional que se brinda de manera tan generosa para hacer la guerra, se debería traducir en apoyo a los esfuerzos económicos de los pobres por abandonar tal condición de degradación humana.

Esta vía representa una acumulación de fuerzas económicas, sociales y políticas que desembocan en el control del poder estatal, conseguido el cual se potencia en gran medida el desarrollo del sector popular de la economía y a la par se irían realizando una serie de ade- 
cuaciones superestructurales a fin de estimular y desarrollar una nueva ideología, unos nuevos valores, etc.

Los procesos revolucionarios "clásicos" tienen un aporte importante en materia ideológica y axiológica, la cual se va generando durante el proceso revolucionario; una transición pacífica vía elecciones, presupone, sin embargo que existe una importante masa crítica al sistema capitalista y de que una u otra manera ha logrado una nueva visión ideológica y que tiene una conducta y unos principios, propios de lo que podría considerarse como un ser humano nuevo, con todo, cabría suponer que existe una significativa proporción de la sociedad que comparte, que apoya y que está dispuesta a implementar un proyecto de sociedad nuevo y alternativo al existente. Lo cual, presupone también la transparencia en los fines y objetivos del partido que ha sido votado por la mayoría de los electores.

Debemos destacar este último elemento, ya que, al sostener que la democracia perfecta es aquella en la que no existen partidos políticos, no queremos decir que los partidos deban desaparecer ya. Por el contrario, se requiere de políticos y partidos que estén dispuestos a construir una nueva sociedad en la cual no tendrían cabida, pero que conseguirlo depende de ellos en gran medida. Lo cual refleja de alguna manera nuestra concepción noble del político, del auténtico político que se debe a la sociedad y no a si mismo.

La segunda vía tiene un componente político importante, ya que se trata de ir accediendo al poder local, para construir desde las localidades una nueva organización económica fundamentada en las OEP. Pero también resulta importante conseguir diputados que confíen en la capacidad del pueblo organizado, no sólo para salir de la pobreza, sino para ir construyendo los elementos de una sociedad alternativa. Su aporte se vería traducido en una legislación que protegiera y apoyara los esfuerzos de toda la población integrada en OEP, así como de las ONG vinculadas con las mismas. De igual manera se podría aprovechar la ola privatizadora para que los trabajadores tuvieran acceso a los activos públicos, para ello sería valioso el aporte de los diputados emitiendo leyes y decretos en tal sentido. Desde esta perspectiva, la privatización podría constituirse en un factor importante de creación de la nueva sociedad. Y la discusión no estaría centrada en si se privatiza o no se privatiza, sino en que efectivamente se posibilite democratizar la propiedad.

Un segundo momento que presenta la segunda vía es la conquista del gobierno central, la cual permitiría fortalecer el sector popular de la economía, esto es, el integrado por las OEP, para ello se requeriría 
mecanismos de transferencia de excedentes del sector capitalista al sector popular, tales como impuestos y subsidios, tipo de cambio, créditos preferente, asistencia técnica, etc.

La tercera vía estaría fundamentada en un pacto obrero-patronal, mediante el cual los propietarios capitalistas transfieran un porcentaje mayoritario de las acciones de sus empresas a los trabajadores, a cambio de congelar salarios, no efectuar huelgas y elevar la productividad y la intensidad del trabajo. Esta vía por sí sola sería la más lenta, e inclusive, de dudosa eficacia en cuanto a la configuración de la nueva sociedad; sin embargo, no debería descartarse, ya que posibilita siempre a los trabajadores tener acceso a la propiedad y en la medida que se avance en las otras vías, se llegaría a un momento en que las formas capitalistas habrían perdido su importancias absoluta y relativa dentro de la sociedad y esta vía podría acelerar su cancelación.

La cuarta vía se originaría en un acuerdo entre el gobierno e inversionistas extranjeros, quienes recibirían una serie de concesiones a cambio de transferir la propiedad de sus inversiones a sus trabajadores luego de un determinado tiempo pactado de común acuerdo. Esta vía presupone que las fuerzas progresivas hayan asumido el control del poder político a nivel nacional.
La quinta vía presupone un escenario de muchísima inestabilidad política y social, fruto de una crisis económica generalizada, la cual Ilevaría a que muchas empresas quebraran. Tales empresas serían absorbidas por el estado, restablecidas y entregadas a los trabajadores. O bien pudiera ocurrir que los trabajadores sencillamente ocuparan las mismas para cobrarse los pasivos laborales y el gobierno legitimaran tal acción mediante una ley de emergencia. Al igual que la vía anterior presupone el control del poder político.

La sexta vía, que denominaremos la vía agrarista, estaría fundamentada en la realización o consolidación de procesos de reforma agraria integrales, los cuales desembocarían en la constitución de OEP. La lucha por la tierra no es aún una acción caduca para muchos trabajadores en el mundo, particularmente en el tercer mundo y en los países ex-socialistas.

La séptima vía sería propia de los países ex-socialistas, en los cuales la propiedad estatal se convirtiera en propiedad de los trabajadores y creara OEP. Esta vía sería de gran importancia en términos mundiales y podría demostrar la viabilidad del sistema en el corto plazo.

La gran resultante de todo este período transicional sería que cuantitativamente el sector popular de la 
economía, en términos de empleo sería muchísimo más importante que el sector capitalista de la economía y en términos del PIB se iría avanzando hasta alcanzar una proporción significativa. En tales condiciones se podría ganar fácilmente el gobierno, o bien conservar el poder previamente ganado y resistir cualquier boicot proveniente del sector burgués de la economía aún con su suficiente fuerza como para no admitir su derrota histórica.

Es preciso explicitar que durante el período de transición el gobierno tiene que satisfacer con responsabilidad y eficiencia todas las necesidades sociales de la población pobre y marginada, pero procurando no realizar una labor meramente asistencialista, sino promotora de la organización económica entre los sectores pobre y marginados, esto es, ampliar la base social del nuevo sistema aún en germen.

\subsection{Las tareas inmediatas}

Las fuerzas progresistas y de izquierda deberían de centrar sus esfuerzos en ampliar la organización de la base económica popular. Dedicar la mayor cantidad de tiempo y recursos a promover la organización de los informales urbanos, a conocer sus necesidades y sus propuestas de solución y a acompañarlos en sus luchas y acciones. Esta es una tarea prioritaria que posibilitaría acceder al control de las alcaldías de los principales núcleos pobla- ciones y a un número significativo de legisladores. De igual manera es importante la organización de las comunidades marginales urbanas a través de sus luchas por satisfacer sus necesidades sociales: agua, luz, vivienda, salubridad, etc. Fortalecer el trabajo en las cooperativas y ampliar la organización campesina, mediante acciones reivindicativas y promotoras del desarrollo económico. Igualmente deberían de replantarse el trabajo realizado en el pasado con los gremios, asi como con los sectores sindicales y con las asociaciones de empleados públicos y municipales. ${ }^{9}$

Por otra parte, es claro que OEP existen muchísimas en el mundo, aunque se conozcan como sociedades o asociaciones cooperativas, como asociaciones comunales, como grupos solidarios, etc. y no se re-conozcan como elementos de una misma especie, de allí que sea preciso en primer lugar, propiciar el que entren en contacto entre sí, a nivel nacional, a nivel centroamericano, latinoamericano y mundial, de manera que compartan sus experiencias y se solidaricen entre si, como partes que son de un todo mayor: los gérmenes del socialismo popular.

En segundo lugar, es importante propiciar la creación de asociaciones que las aglutinen a nivel nacional, centroamericano, latinoamericano y mundial, lo cual les daría mayor fortaleza y posibilitaría que compartieran un proyecto común. 
En tercer lugar, una vez establecido los contactos entre si, habría que propiciar el que establecieran relaciones económicas entre si; antes que con empresas capitalistas, de esta manera no sólo reducirían las relaciones de expoliación, sino que adicionalmente potenciarían su propio desarrollo.

En cuarto lugar, habría que propiciar su participación en las redes de comercio alternativo que existen en Europa y los E.U., esto no sólo les posibilitaría ampliar su actividad económica y obtener mejores precios, sino que a su reduciría los riesgos de depender de un mercado controlado mayoritariamente por empresas capitalistas.

En quinto lugar, aprovechar todos los proyectos de agencias nacionales e internacionales de apoyo a la microempresa, a la mujer, al medio ambiente, etc. Reactivar contactos o establecerlos con organismos promotores del cooperativismo a nivel mundial. Ampliar los programas de ciudades hermanas, etc.
En sexto lugar, revitalizar los apoyos solidarios con los pueblos del tercer mundo, en su lucha contra la pobreza y la marginación social, ahora fundamenta en su propio esfuerzo organizativo y productivo, mediante la elaboración y "venta" de proyectos económicos concretos de desarrollo.

En séptimo lugar, que las fuerzas progresistas y de izquierda asuman este proyecto como propio, se replanteen su quehacer político y se creen las estructuras necesarias para implementarlo.

Como se puede apreciar en las acciones propuestas, nuestra preocupación se ha centrado en la realidad particular del tercer mundo. Ello es así en razón de que si buscamos hacer operativa la estrategia es preciso abocarse a lo concreto y específico; sin embargo, acciones semejantes podrían proponerse para otros países dependiendo de cuales sean sus problemas y sus potencialidades.

\section{Reflexiones finales.}

Dos cuestionamientos que suelen ser tradicionales cuando se realiza cualquier tipo de propuesta son los referidos a la viabilidad y a la factibilidad, con el agravante de que suelen usarse en el mismo sentido y con la misma intencionalidad: esto es, lo inútil, lo inoficioso y lo sin sentido que resulta el andar haciendo propuestas utópicas. Y calificar de utópico a algo, significa descalificarlo a priori. A la utopía -al realismo utópico, diríamos nosotros- se contrapone el falso realismo pragmático, el cual no es realista, ni pragmático ya que sencillamente se trata de una modalidad de conservadurismo interesado. El cual se 
suele presentar en lo económico, en lo político, en lo ideológico y en el pensamiento mismo, que ha operado temporalmente con relativo éxito a lo largo de la historia humana. Se suele esconder tras una fingida responsabilidad social y entre los profesionales es muy común encontrarlo entre aquellos mediocres incapaces de pensar por cuenta propia, pero muy hábiles para repetir hasta la más oscuras teorías propias de los organismos internacionales.

¿Será viable un sistema socioeconómico como el propuesto? Es obvio que nuestra respuesta es que no sólo es viable, en términos económicos, sociales y políticos, sino a su vez es deseable, ya que no sólo enfrenta y resuelve los problemas socio-económicos fundamentales del capitalismo y del ex-socialismo europeo, sino que adicionalmente ofrece una alternativa muy prometedora e inédita a los trabajadores de ambos sistemas. Veamos únicamente el aspecto económico, si confiamos en la viabilidad económica de un sistema como el capitalista que está fundamentado en la libre empresa y en la iniciativa individual, ¿por qué habría de ser inviable un sistema económico y social fundamentado en las OEP, donde son los trabajadores-propietarios los responsables de la actividad económica? ¿Qué es lo que se ha sacrificado en términos de viabilidad económica? Nada. ¿Acaso no son los presidentes, los gerentes, los directorios de las empresas quienes las dirigen? Y tales figuras no tendrían porque desaparecer en el modelo propuesto, aunque se verían complementadas con la participación, con la iniciativa y la colaboración de todos los trabajadores-propietarios, quienes tendrían sobradas razones e intereses para trabajar de manera eficiente.

¿Será factible la propuesta del socialismo popular? Entendiendo por tal pregunta el que se pueda instaurar tal modalidad de socialismo, añadiendo a continuación: ¿Lo permitirá la burguesía, el gobierno, los Estados Unidos? Para añadir a continuación. Se trata de una propuesta que va contra corriente, lo cual la hace ser poco realista. Preguntarle a la utopía acerca de su factibilidad histórica, no deja de resultar una pregunta necia, ya que de antemano se sabe cual es la respuesta. A menos que se crea en las profecías de Nostradamus y en tal caso, resultaría más apropiado consultar con alguno de sus intérpretes más calificados y no con aquellos, para quienes la utopía se nos presenta como lo no realizado, es cierto, pero con una existencia lógica a nivel del pensamiento, lo cual puede convertirla en una idea fuerza y consecuentemente, motivar la acción consciente del fin perseguido.

Es obvio que la respuesta a tal pregunta sólo se encuentra en el futuro, pero también es obvio que, cuál sea el futuro dependerá 
de cuáles sean nuestras acciones presentes. El futuro no cae de pronto del cielo, sino que se va construyendo día con día. Es por tal razón que se señalan una serie de acciones que es preciso realizar, si realmente se desea avanzar hacia el futuro propuesto.

Por otra parte, si conocemos la historia para servirnos de ella y no sólo para demostrar cuán eruditos somos, preciso es reconocer que el camino que se le presentaba a la naciente burguesía en el seno del régimen feudal, era muchísimo más escarpado, existían más poderes aparentemente más fuertes y poderosos que aquellos por vencer

Notas

1. Se agradece a Antonio González, S.J. habernos animado a iniciar este trabajo. Ojalá y sirva para algo.

2. Manifiesto salvadoreño, ANEP, 1996, p. 21

3. El socialismo en la Europa oriental, más que representar un avance en el desarrollo histórico de la humanidad, parecía una organización social que recordaba al modo de producción asiático o tributario en su fase de descomposición, donde la clase dirigente se había convertido en una clase explotadora, sin que existiera propiedad privada de los medios de producción.

4. Si insistimos en diferenciar a los medios de producción -maquinaria, equipo, edificios, materias primas y auxiliares- de los medios de circulación-locales, dinero, mercadería, ahora, no existía una experiencia clara de cómo hacer la historia; sin embargo, los intelectuales burgueses armados de unas cuantas ideas fuerza se lanzaron a derrotar el feudalismo y aunque no crearon la sociedad que prometieron, vean que no ha sido poco lo que consiguieron.

El socialismo popular, ¿qué le ofrece al mundo? Le ofrece vida, mientras que el capitalismo niega la vida, toda forma de vida. El socialismo popular ofrece vida, vida para todos. Y las cosas se pueden plantear aún de manera más senciIla: ¡O acabamos con el sistema o el sistema acaba con nosotros!

etc- es porque se preserva el mercado y con él la circulación.

5. La organización económica popular es el término genérico para referirse a cualquier forma de organización económica, como podrían ser, por ejemplo, las asociaciones y las sociedades cooperativas, las sociedades anónimas laborales, los grupos solidarios y cualquier forma organizativa de los trabajadores con fines económicos.

6. Por desarrollo sostenible entendemos un estilo de desarrollo ambientalista, más próximo a la concepción del ecosocialismo ecológico que a la visión del Informe Brundtland.

7. Asociaciones es el nombre genérico para referirse a cualquier forma de organización colectiva, cuales son por ejemplo: colegios profesionales, 
gremios, sociedades, asociaciones, cámaras, etc.

8. La nueva economía popular: una aproximación teórica; La nueva economía popular: una aproximación empirica; Informalidad urbana y nue- va economía popular, UCA Editores, 1993, 1994 y 1995, respectivamente.

9. Sobre el particular, sería conveniente aprovechar las experiencias del Partido de los Trabajadores del Brasil. 